\title{
Auxerre, études archéologiques à l'intérieur de la cathédrale Saint-Étienne
}

\section{Christian Sapin}

\section{Q OpenEdition}

1 Journals

\section{Édition électronique}

URL : https://journals.openedition.org/cem/2932

DOI : $10.4000 /$ cem.2932

ISSN : 1954-3093

Éditeur

Centre d'études médiévales Saint-Germain d'Auxerre

\section{Édition imprimée}

Date de publication : 15 août 2003

ISSN : 1623-5770

\section{Référence électronique}

Christian Sapin, «Auxerre, études archéologiques à l'intérieur de la cathédrale Saint-Étienne », Bulletin du centre d'études médiévales d'Auxerre | BUCEMA [En ligne], 7| 2003, mis en ligne le 19 octobre 2007, consulté le 22 septembre 2022. URL : http://journals.openedition.org/cem/2932 ; DOI : https://doi.org/ 10.4000/cem.2932

Ce document a été généré automatiquement le 22 septembre 2022.

\section{cc) (†) (5)}

Creative Commons - Attribution - Pas d'Utilisation Commerciale - Partage dans les Mêmes Conditions 4.0 International - CC BY-NC-SA 4.0

https://creativecommons.org/licenses/by-nc-sa/4.0/ 


\title{
Auxerre, études archéologiques à l'intérieur de la cathédrale Saint- Étienne
}

\author{
Christian Sapin
}

\section{Élévation mur ouest}

1 Les recherches archéologiques sur le site de la cathédrale Saint-Étienne d'Auxerre, menées avec la collaboration de Harry Titus, ont porté en 2002 d'une part sur l'emplacement du mur occidental de la cathédrale romane et, d'autre part, sur la question des accès à la crypte. Les recherches sur la position du mur occidental ont été dictées par les résultats de la prospection géophysique de 1998 qui avaient permis de visualiser un secteur précis. En juin 2002, une fouille limitée a reconnu la présence d'un mur de 2,10 $\mathrm{m}$ d'épaisseur, avec en plus un ressaut de $0,70 \mathrm{~m}$ qui pourrait correspondre à un contrefort encadrant un dispositif d'entrée. Les couches de remblai placées au moment de la fondation comportent du mobilier céramique avec des bords en bandeau des $\mathrm{X}^{\mathrm{e}}-\mathrm{XI}^{\mathrm{e}}$ siècles. Il existe également de la céramique résiduelle du $\mathrm{VI}^{\mathrm{e}}$ ou $\mathrm{IX}^{\mathrm{e}}$ siècle. $\mathrm{Au}$ plus bas du sondage, la structure reposait en partie sur la démolition d'une autre maçonnerie constituée d'un mortier identique à celui identifié lors des fouilles de l'avant-nef et de la crypte pour la phase carolingienne de l'abbaye Saint-Germain d'Auxerre.

\section{Crypte}

2 Dans la crypte de la cathédrale, l'examen des maçonneries de l'accès bouché au nordouest de la salle centrale a permis de déterminer un état originel (début $\mathrm{XI}^{\mathrm{e}}$ siècle) correspondant à un système de niche murale identique à celle encore conservée au centre du mur occidental. L'accès se faisait alors latéralement par des ouvertures encore visibles, mais bouchées lors de l'édification du chœur gothique au début du XIII ${ }^{\mathrm{e}}$ siècle. L'étude des mortiers et des techniques de taille de pierre de l'encadrement des ouvertures crées dans les niches à l'ouest indique cependant que celles-ci ont été pratiquées à la fin du $\mathrm{XI}^{\mathrm{e}}$ siècle ou au début du XII ${ }^{\mathrm{e}}$ siècle pour répondre sans doute à des besoins liturgiques différents. Par ailleurs, un sondage pratiqué dans la partie nord 
du déambulatoire n'a pas confirmé l'existence d'un accès direct depuis l'évêché dans la crypte, mais a reconnu le ressaut du mur de fondation du déambulatoire crée dans un remblai de terre antérieur et encore en place dans ce secteur.

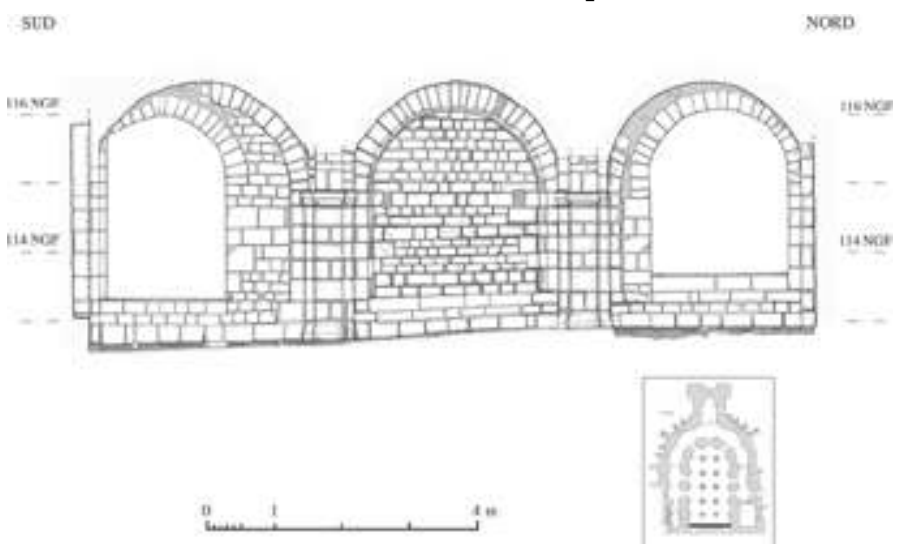

Auxerre, cathédrale Saint-Étienne, crypte - zone occidentale. Élévation du mur ouest (dessin G. Fèvre CEM).

INDEX

Index géographique : France/Auxerre

Mots-clés : cathédrale, Saint-Etienne d'Auxerre 